\title{
Bacillus cereus \& Bacillus pumilus Harvested from a Copper Roof Inhibit the Growth of Other Microorganisms
}

\author{
Alison Stiller*, Ashley Fink, \& David Mitchell** \\ Department of Biology, College of St. Benedict / St. John's University, Collegeville, MN \\ bttps:/ / doi.org/10.33697/ ajur.2020.016 \\ Student: astiller001@csbsju.edu* \\ Mentors:afink001@,csbsjue.edu,dmitchell@csbsju.edu**
}

\begin{abstract}
Bacteria growing under the effects of unique selective pressures have distinct adaptations allowing them to survive. Copper surfaces present challenges for bacterial survival because ions dissolve from the surfaces and disrupt cell membranes, thus inhibiting bacterial growth. In this study, the copper roof of Simons Hall in Collegeville, Minnesota was sampled for bacterial species during November 2018. Bacteria were isolated and grown in culture, and zones of inhibition were identified surrounding three of the bacterial colonies. Polymerase chain reaction (PCR) was used to identify two of the bacteria samples as Bacillus cereus and a third sample as Bacillus pumilus. Bacilli are large, rod-shaped, gram-positive bacteria commonly found in diverse environments. They are endospore-forming aerobes or facultative anaerobes. Initial experiments indicated that all three Bacillus strains had the ability to inhibit the growth of three environmental microorganisms. Results from growth curve experiments depicted inhibitory effects on environmental microorganisms at all stages of the growth curve, which is contrary to the prediction that the inhibitory behavior would appear at one specific period of the growth curve. Additional experiments involved plating isolates of Bacillus cereus and Bacillus pumilus with laboratory samples of Pseudomonas aeruginosa, Streptococcus pneumoniae, and Listeria monocytogenes to further understand the effectiveness of B. cereus and B. pumilus at inhibiting the growth of other microorganisms. These findings support previous studies and suggest that Bacillus are capable of inhibiting or killing other organisms. Further research will be conducted to illuminate the inhibitory mechanisms and identify potential therapeutic possibilities.
\end{abstract}

\section{KEYWORDS}

Bacteria; Copper; Resistance; Growth Curve; Inhibition; Bacillus; Bacteriocin; Antimicrobial Peptides

\section{INTRODUCTION}

Bacteria are capable of inhabiting a wide variety of environments; however, some factors present challenges for bacterial growth. For example, limited food or water, excessive competition, and specific ions present unique pressures that microorganisms may develop advantages to overcome. Specifically, copper ions dissolve from copper surfaces, which disrupt the cell membrane and cause the loss of membrane potential and cytoplasmic content. Further, reactive oxygen species (ROS), such as those generated by copper ions, degrade cytoplasmic and genomic DNA. Contact killing of microorganisms on copper was observed to occur at a rate of at least seven to eight logs per hour. ${ }^{1}$ Thus, as an application of the common notion that copper surfaces exhibit antimicrobial properties, hospitals and laboratories have implemented the use of copper surfaces in an effort to eliminate possibilities for contamination or spread of unwanted microorganisms. ${ }^{2}$

Although copper has been studied extensively for its toxic effects, there are microorganisms with adaptations allowing survival on copper surfaces. These microorganisms may have a competitive advantage in situations where copper is implemented for its antimicrobial effects. For example, bacterial samples previously isolated from a copper mine environment included Acidovorax, Acinetobacter, Bacillus, Brevundimonas, Stenotrophomonas, Kocuria, Roseomonas, Pseudomonas, and Bacillus was the most abundant and diverse in this environment. ${ }^{3}$ Bacilli are large, rod shaped, gram positive, and endospore-forming aerobes or facultative anaerobes. The formation of endospores allows their resistance to heat, cold, radiation, desiccation, and disinfectants, thus they are able to inhabit a variety of environments that would otherwise inhibit bacterial growth. ${ }^{4}$ They are common environmental organisms and are often the source of contamination in media and specimens in laboratories. ${ }^{5}$ Bacilli can be found in diverse environments such as in gastrointestinal tracts of animals and insects, as well as in aquatic environments, food, soil, vegetation and rocks. ${ }^{6}$ Bacilli exhibit additional competitive abilities against antibiotics and are one type of bacteria that produce $\beta$-lactamase which enables them to grow in the presence of beta lactam drugs, such as penicllin. ${ }^{7}$ Further, antibiotic resistant plasmids have been isolated from Bacillus cereus. ${ }^{8}$ 
Starvation in some strains of Bacilli activates processes that promote survival under nutritional stress, including the development of genetic competence, sporulation, synthesis of degradative enzymes, motility, and antibiotic production. ${ }^{9}$ Antimicrobial peptides synthesized by bacterial ribosomes are commonly classified as bacteriocins. Bacteriocins are classified by size, shape, and whether or not they possess lanthionine (or $\beta$-methyllanthionine) residues. ${ }^{10}$ Previously, a Bacillus bacteriocin displaying antimicrobial activity against both gram-positive and gram-negative bacteria was isolated and classified. The bacteriocin also displayed stability across wide ranges of temperature and $\mathrm{pH}$. This phenomenon was proposed to be due to unusual amino acids in the antimicrobial substances. The mechanism of bactericidal action was reported to be pore formation on the bacterial cell membrane, thus compromising its integrity. 11

Other investigators have shown the usefulness of Bacillus bacteriocins. For example, Subtilosin A was developed from Bacillus subtilis 168 bacteriocins and has bactericidal activity against some gram-positive bacteria that are pathogenic to humans. ${ }^{12}$ Bacillus bacteriocins are also being investigated as toxic to other bacteria and results are being reported in human health fields including the control of pathogenic bacteria such as MRSA, G. vaginalis, and C. difficile. ${ }^{13}$ In addition to studies evaluating the potential of Bacilli in producing antibacterial bacteriocins, there have been studies evaluating compounds that have toxic effects on protozoa and fungi. Bottone et al. described a compound produced by Bacillus pumilus that was able to inhibit spore germination and hyphal elongation in Mucoraceae and Aspergillus. ${ }^{14}$

The discovery of naturally synthesized antimicrobial compounds by Bacillus species has been ongoing and abundant. In this study, Bacillus cereus and Bacillus pumilus were isolated from a copper roof. The roof was sampled as an attempt to identify bacteria able to thrive in an environment devoid of many life promoting properties. The isolated Bacillus species were surviving in the environment yet under the pressure of the copper surface. It was hypothesized that the bacteria isolated from the copper roof were able to produce an inhibitory molecule or compound, such as a bacteriocin, during a specific period of their growth that would allow them to prevent other bacteria from growing near them.

\section{METHODS AND PROCEDURES}

\section{Isolation and Identification}

Sterile cotton swabs were used to sample the copper roof of Simons Hall on the Saint John's University Campus in November 2018. The samples were then swabbed onto trypticase soy agar (TSA) plates and allowed to grow for one week at $20^{\circ}$ Celsius (Figure 1). Three distinct colonies (initially labelled 1, 2, and 4) were isolated along with three nearby colonies $(10,11,12)$ from the mixed culture plate and identified by 16s rRNA PCR.

\section{6s rRNA Polymerase Chain Reaction}

Pure cultures of the three bacterial species $(1,2,4)$ were subject to PCR amplification using universal primers U341F and UA1406R that recognize an 1100bp segment of the 16s rRNA gene. PCR products were run on a 1.5\% agarose gel and confirmed to be 1100 bp in length. PCR products were then purified (QIAquick PCR Purification Kit, QIAGEN), pre-mixed with the forward universal primer U341F and sent to GeneWiz (South Plainfield, NJ) for sequencing. FASTA files were then used in a BLAST and the ARB-SLIVA project aligner to identify the most likely genus and species of each organism. Bacterial samples 1 and 2 produced significant alignment for Bacillus cereus strain SKH $16 \mathrm{~S}$ rRNA gene with a 99.60\% identity (Accession KJ685393.1). Bacteria sample 4 produced alignment for Bacillus pumilus strain 17 16S rRNA gene with a $99.20 \%$ identity (Accession MK621233.1).

\section{Antimicrobial testing}

Following growth of the microorganisms on TSA, it was observed that some colonies were surrounded by clear zones of no growth (inhibition) suggestive of an ability to impact the growth of other microorganisms in a population (Figure 1). We identified samples 1,2 and 4 as potentially having antimicrobial properties against samples 10,11 and 12. To test this, TSA plates were simultaneously streaked with either 1,2 or 4 at the center black line and at the smaller lines with 10,11 or 12 . These plates were then incubated at room temperature and checked for zones of inhibition two days later (Figure 2). This test was repeated as shown in Figure 3 but with the difference that isolates 1, 2 and 4 were streaked on plates one day before 10, 11 or 12 or the opposite.

In a second experiment, the antibiotic capabilities of Bacillus pumilus (4) were tested by picking colonies using sterile toothpicks and inoculating $3 \mathrm{~mL}$ of Tryptic Soy Broth (TSB) overnight at $27^{\circ} \mathrm{C}$. The following morning, $150 \mu \mathrm{L}$ of the culture was used to inoculate $50 \mathrm{~mL}$ of TSB in $250 \mathrm{ml}$ Erlenmeyer flasks. Nine flasks (A-J) were then shaken at 150 RPM in a New Brunswick Scientific C25 floor shaker set at $27^{\circ} \mathrm{C}$. Lawns of environmental sample 12 were made on TSA plates at the same time as the overnight tubes were inoculated. At the times shown on the sample plates in Figure 4a, $25 \mu \mathrm{L}$ from a given flask was pipetted onto the lawn using sterile pipette tips. Growth of the bacteria in the Erlenmeyer flask was monitored by measuring optical density at $600 \mathrm{~nm}$ using a Beckman Coulter DU640 ultraviolet/visible spectrophotometer. 
In a third experiment (Figure 5), liquid inoculum of environmental microbe 12 was individually spread on TSA plates using sterile swabs in order to create a bacterial lawn. Immediately after inoculating the bacteria on the TSA plates $25 \mu \mathrm{L}$ of Bacillus cereus $a$ and Bacillus cereus $b(1,2)$ were added to each of the plates. This procedure was repeated with cultures of Bacillus at different stages in the growth curve, as described above. All bacterial cultures were used in these experiments immediately after recording the $\mathrm{OD}_{600}$ and agar plates were incubated at room temperature.

A fourth experiment involved plating isolates of Bacillus cereus and Bacillus pumilus with laboratory samples of Pseudomonas aeruginosa, Streptococcus pneumoniae, and Listeria monocytogenes to further understand the effectiveness of B. cereus and B. pumilus at inhibiting the growth of other organisms. Two sets of lawns were made for each Bacillus strain. The lawns were made by placing two sterile test tube caps upside down on the TSA plates about 1 inch apart. The lawn of the selected bacteria was then made around those caps. The circumference of the caps was marked on the plate as a reference. One set of lawns was made the day before Bacillus strains were plated and one set was made at the same time Bacillus strains were plated. On each plate, killer 1a/b (B. cereus) and killer 4a/b (B. pumilus) were plated in the spaces left by the test tube caps. Two tubes of each Bacillus strain were inoculated in tryptic soy broth (TSB). This was denoted as $\mathrm{T}_{0}$. At $\mathrm{T}_{0}, 100$ microliters $(\mu \mathrm{L})$ of Bacillus was plated. The broth cultures of the Bacillus strains were shaken at $27^{\circ} \mathrm{C}$ at $150 \mathrm{RPM}$ and were taken out and plated at the two-hour intervals. All of the plates were left to grow overnight at $20^{\circ} \mathrm{C}$.

\section{RESULTS}

Saint John's University is set amid 2,700 acres of land in rural, Collegeville Minnesota. In November 2018 the copper roof of one of the academic buildings was sampled to obtain microorganisms that were able to survive in the presence of copper (Figure 1). Over twelve different types of colonies were observed on the TSA agar plates following incubation at $20^{\circ} \mathrm{C}$. Interestingly, there were obvious zones of inhibition apparent surrounding three of the colonies (Figure 1).

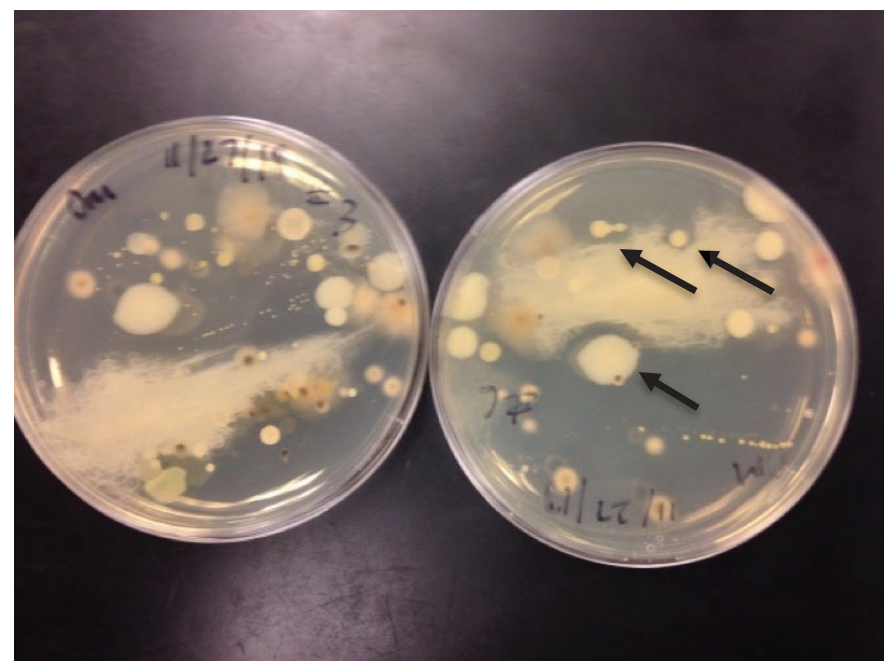

Figure 1. Microbial growth on TSA plates obtained by swabbing the copper roof of Simons Hall with sterile swabs. The diameters of the zones of inhibition around the top left, top right, and bottom colonies are $5.6 \mathrm{~mm}, 8.8 \mathrm{~mm}$ and $26.4 \mathrm{~mm}$, respectively.

The three colonies that displayed zones of inhibition surrounding their growth were further characterized and identified as Bacillus cereus a, Bacillus cereus $b$, and Bacillus pumilus. To determine whether the growth inhibiting properties of these three species depended on the phase of the growth at which they were introduced to environmental microbes, Bacillus cereus a, Bacillus cereus b, and Bacillus pumilus (1, 2, and 4, respectively; Figure 2) were streaked simultaneously with the environmental microbes (microbes whose growth was inhibited and isolated from the same agar plates in Figure 1; 10,11,12). All three Bacillus species displayed patterns of inhibiting the growth of the environmental microbes with the Bacillus pumilus displaying the most potent antimicrobial activity with the largest zone of inhibition, $22.0 \mathrm{~mm}$ (Figure $2 \mathrm{c}$ ).

In order to determine if the Bacillus species could still produce antimicrobial compounds and inhibit the growth of already established and growing environmental microbes, the environmental microbes $(10,11,12)$ were streaked diagonally across TSA agar plates and allowed to grow for 24 hours. The three Bacillus species were then introduced by streaking parallel lines on either side of the environmental microbes (Figure 3a). These data were compared to a similar experiment where the Bacillus species were first streaked diagonally across TSA agar plates, allowed to grow for 24 hours and then the environmental microbes were 
introduced (Figure 3b). In both experimental designs, the Bacillus species displayed clear zones of inhibition around the environmental microbes.

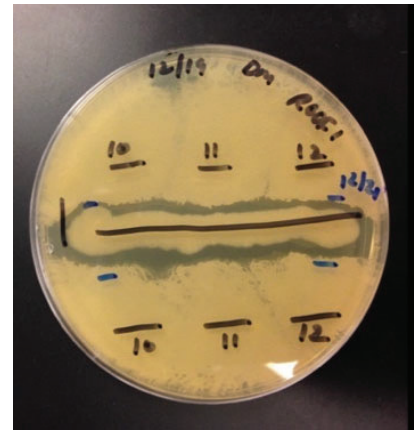

(a)

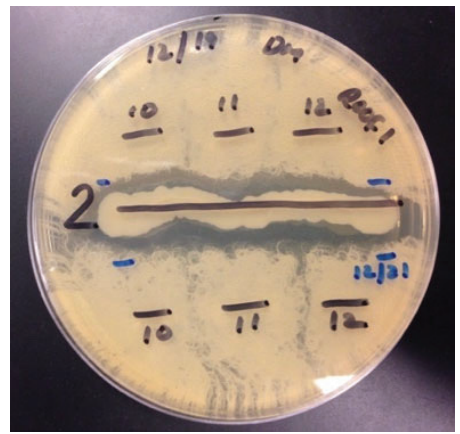

(b)

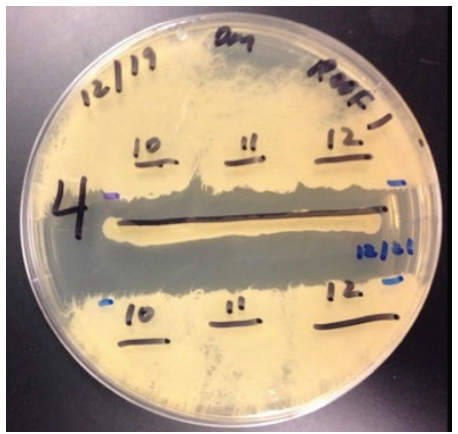

(c)

Figure 2. B.cereus and B.pumilus inhibition of environmental microbes. Bacteria samples were streaked simultaneously (black lines) onto three TSA plates using a sterile cotton tip (a, b, c). Samples 1, 2, and 4 correspond to Bacillus cereus a, Bacillus cereus b, and Bacillus pumilus and were identified as inhibiting the growth of the unknown microbes 10,11, and 12. Blue lines represent the inhibition of samples 1,2, and 4 two days after plates were made. The zones of inhibition for figures a, $\mathrm{b}$, and c are $15.4 \mathrm{~mm}, 16.5 \mathrm{~mm}$, and $22.0 \mathrm{~mm}$, respectively.
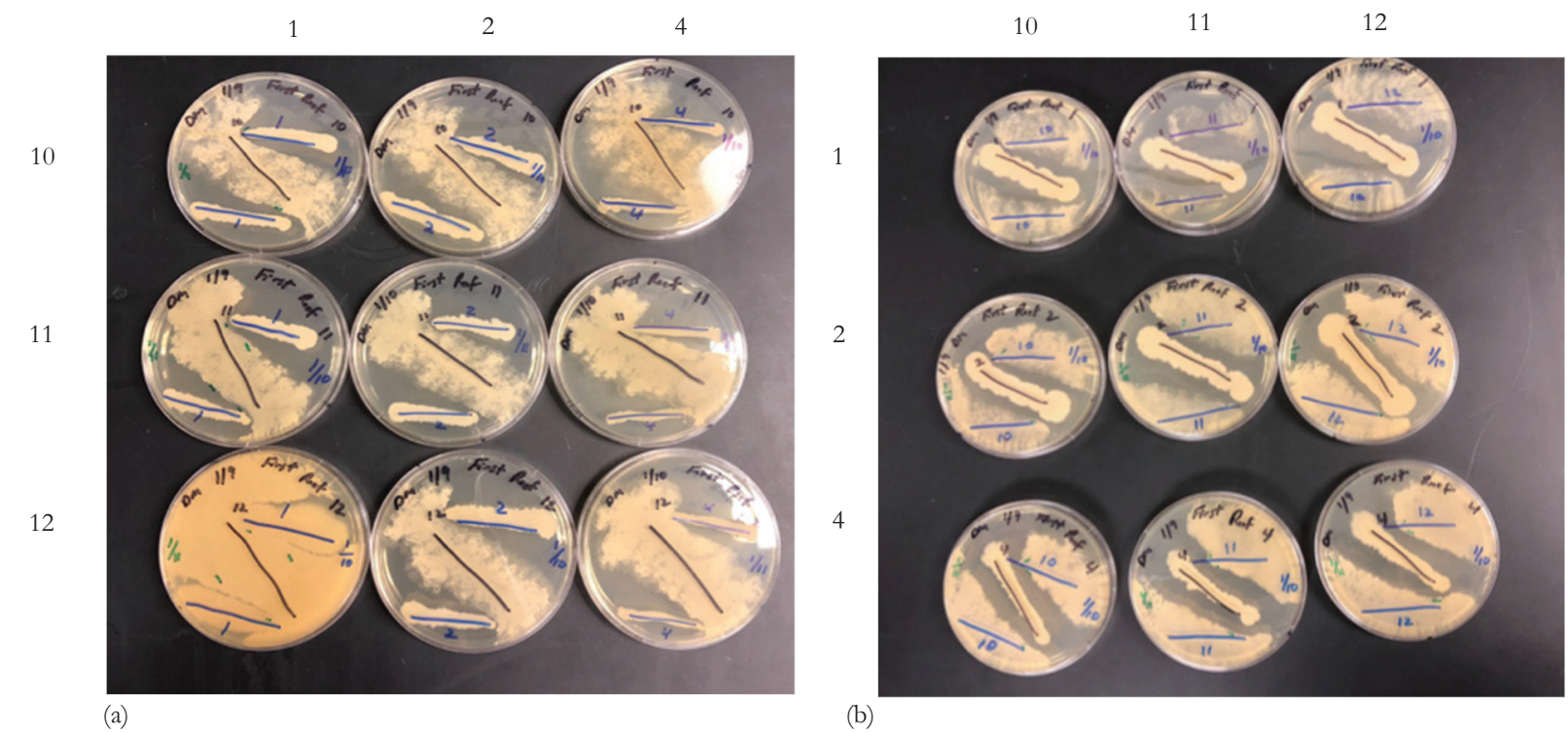

(b)

Figure 3. Qualitative depiction of Bacillus cereus and Bacillus pumilus inhibition of environmental microbes when given a time advantage for growth. (a) Environmental microbes $(10,11,12)$ were streaked on TSA agar plates one day before the introduction of Bacillus cereus a, Bacillus cereus $b$, and Bacillus pumilus (represented by lines 1, 2, and 4 respectively). (b) Bacillus cereus a, Bacillus cereus b, and Bacillus pumilus (1, 2, 4 respectively) were streaked on TSA agar plates one day before the unknown environmental bacteria $(10,11,12)$. Numbers above each figure represent the cultures displayed in parallel lines. Numbers to the left of each figure represents the cultures displayed diagonally.

To specifically evaluate the antimicrobial properties of the proposed Bacillus pumilus bacteriocin, a series of flasks (A-J) were inoculated with Bacillus pumulis and at different time points were inoculated on a 24-hour lawn of environmental microbe 12. Each plate represents a different time (after inoculation in the flasks) at which the Bacillus pumilus was introduced to the lawn of environmental microbe 12 (Figure 4a). Zones of inhibition were observed throughout all nine isolates (A-J). Average zones of inhibition are recorded in Table 1. Antimicrobial properties indicated by the zones of inhibition were present for all inoculum sizes of Bacillus pumilus. (Figure 4b).

\begin{tabular}{|l|l|l|l|l|l|l|}
\hline Time(hours) & 3.5 & 5.0 & 7.0 & 11.5 & 23.25 & 26 \\
\hline Average Zone of Inhibition $(\mathrm{mm})$ & $19.0 \pm 1.5$ & $16.2 \pm 3.7$ & $10.5 \pm 1.2$ & $11.0 \pm 1.9$ & $13.4 \pm 2.5$ & $18.2 \pm 1.8$ \\
\hline
\end{tabular}

Table 1. Average zone of inhibition $(\mathrm{mm})$ for nine colonies of $B$. pumilus as a function of time grown in liquid culture before streaking onto TSA plates with unknown environmental microbe 12 . Environmental microbe 12 was allowed one day of growth prior to streaking $B$. pumilus onto the plate. $\mathrm{n}=9$ 


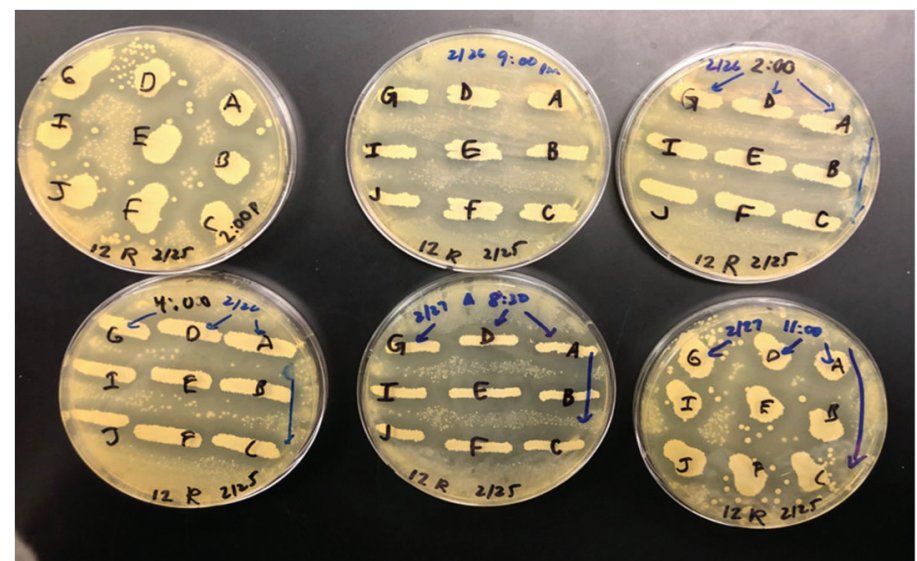

(a)

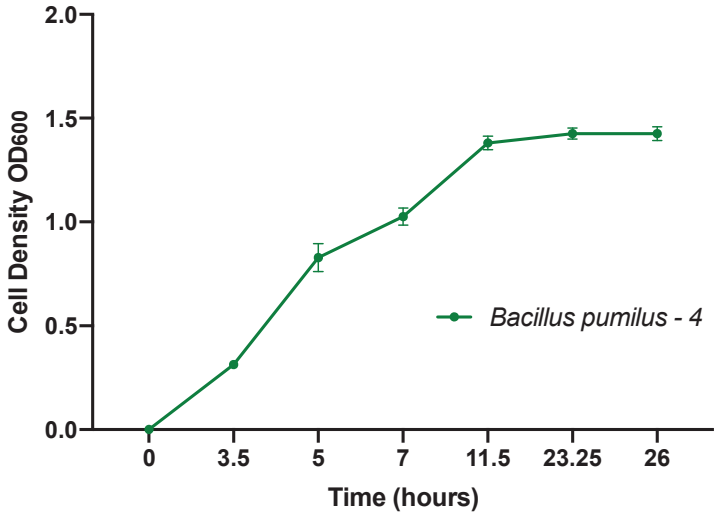

(b)

Figure 4. (a) Bacillus pumilus inhibition of environmental microbes. Environmental microbe (12) was inoculated onto TSA to make a bacterial lawn. One day later, Bacillus pumilus was inoculated onto the agar (represented by letters) at various stages of their growth curves (time points move from top left to lower right). The circular colonies were obtained because a localized sample was pipetted onto the plate and the line colonies were created when a sterile cotton swab was used to inoculate the Bacillus. (b) Bacterial cultures $(\mathrm{n}=9)$ were grown in TSB at $27^{\circ} \mathrm{C}$ with shaking and $\mathrm{OD}_{600}$ measurements were taken at various time points. Average zones of inhibition in chronological order are $18.8 \mathrm{~mm}, 16.9 \mathrm{~mm}, 10.2 \mathrm{~mm}, 10.3 \mathrm{~mm}, 12.4 \mathrm{~mm}$, and $15.8 \mathrm{~mm}$.

To determine the kinetics of when the antimicrobial compounds are produced by the Bacillus species, Bacillus cereus $a$ and $b$ were grown in liquid culture, and at various time points during the growth phase, (Figure 5b) were inoculated on a lawn of environmental microbe 12. The lawns were made at the same time that the Bacillus was introduced, so neither microorganism had a growth time advantage (no previous growth of environmental microbe 12 allowed). As demonstrated in Figure 5a, Bacillus cereus synthesized antimicrobial compounds and this inhibition, or the prevention of growth, of environmental microbe 12 seems to increase with time followed by a decrease at the final time point for B. cereus. Both Bacillus cereus samples $(1,2)$ prevented environmental microbe 12 from growing. Average diameters of the zones of inhibition in chronological order are recorded in Table 2.

\begin{tabular}{|l|l|l|l|l|l|}
\hline Time(hours) & 4.5 & 9.0 & 19.5 & 27.0 & 33.0 \\
\hline Average Zone of Inhibition (mm) & $19.2 \pm 0.46$ & $16.4 \pm 1.3$ & $15.8 \pm 3.3$ & $29.8 \pm 2.8$ & $15.4 \pm 2.8$ \\
\hline
\end{tabular}

Table 2. Average zone of inhibition $(\mathrm{mm})$ for nine colonies of $B$. cereus as a function of time grown in liquid culture before streaking onto TSA plates with unknown environmental microbe 12 . Environmental microbe 12 was not allowed any extra time for growth prior to streaking $B$. cereus onto the plate. $\mathrm{n}=6$
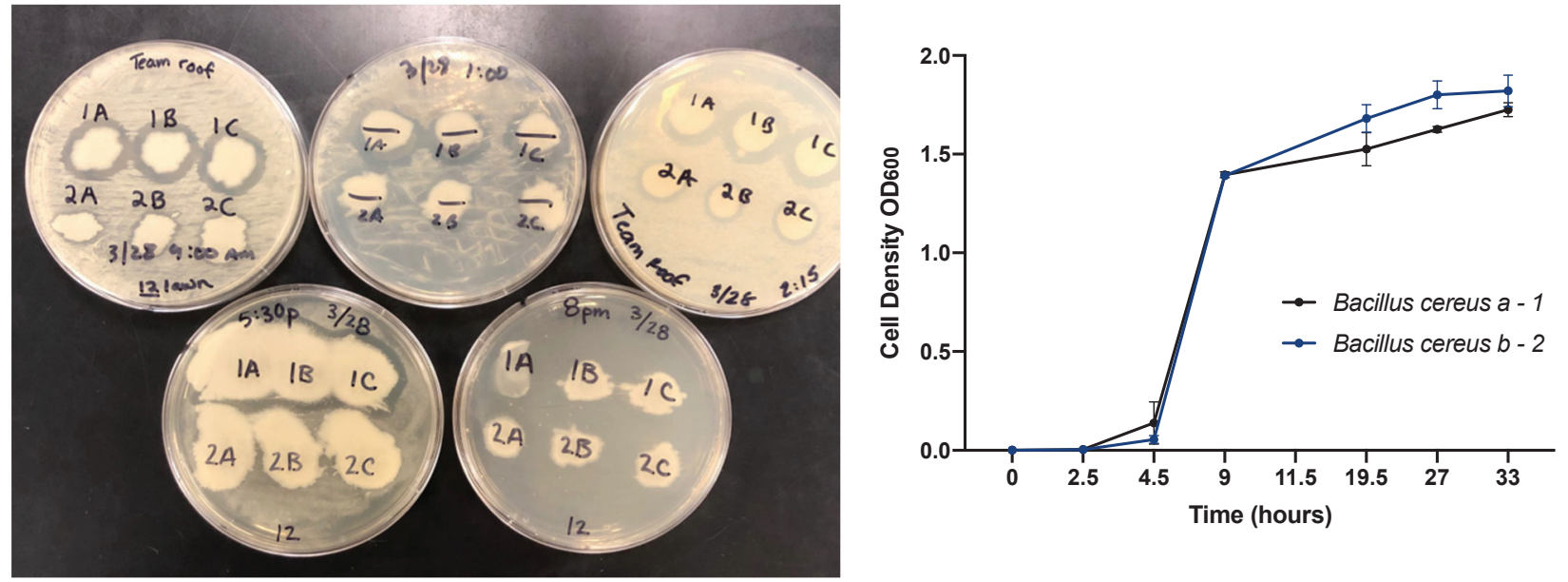

(a)

(b)

Figure 5. (a) Bacillus cereus inhibition of environmental microbes. Environmental microbe (12) was inoculated onto TSA to make a bacterial lawn. Immediately following, Bacillus cereus was inoculated onto the agar (represented by letters) at various stages of their growth curves. (b) Bacterial cultures ( $\mathrm{n}=2$ ) were grown in $\mathrm{TSB}$ at $27^{\circ} \mathrm{C}$ with shaking and $\mathrm{OD}_{600}$ measurements were taken at various time points. Average diameters of the zones of inhibition in chronological order are 22 $\mathrm{mm}, 21.5 \mathrm{~mm}, 19.0 \mathrm{~mm}, 30.6 \mathrm{~mm}$, and $15.6 \mathrm{~mm}$. 
To examine inhibitory properties of Bacilli against other common microorganisms, B. cereus and B. pumilus were plated with laboratory samples of L. monocytogenes, P. aeruginosa., and S. pneumoniae. B. cereus produced zones of inhibition of $27.55 \mathrm{~mm}$ and 26.1 $\mathrm{mm}$ against $L$. monocytogenes when they were inoculated onto the plates on the same day. No zones were measurable when Bacillus \pm baci strains were plated a day before L. monocytogenes. Further, B. pumilus did not produce any zones of inhibition against $L$. monocytogenes. No zones of inhibition were measurable against $P$. aeruginosa for either strain of Bacillus. B. cereus produced a zone of $25.2 \mathrm{~mm}$ in diameter against $S$. pneumoniae when plated on the same day. No measurable zones were produced by $B$. pumilus.

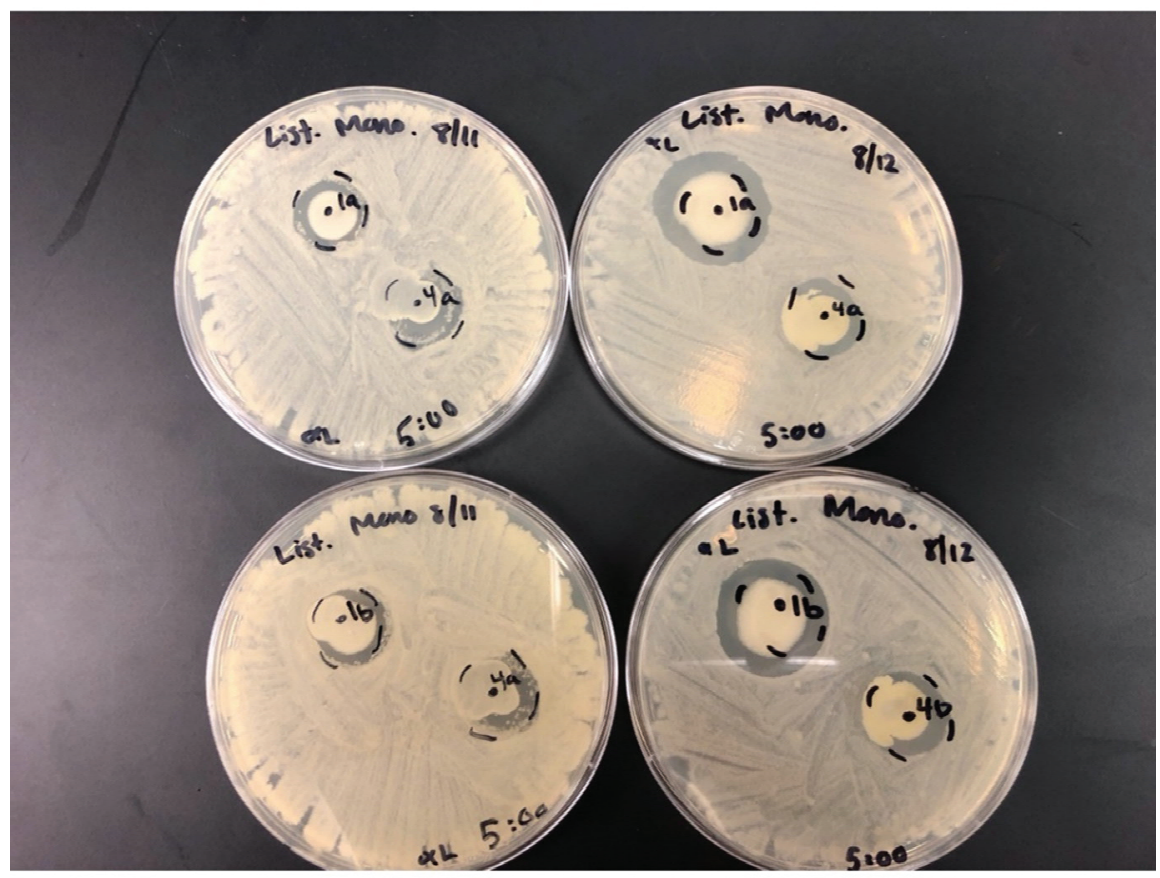

Figure 6. Differences in the zones of inhibition between B. cereus (1A, 1B) and B. pumilus (4A, and 4B) against L. monocytogenes at $\mathrm{T}_{4}$ when Bacillus strains were plated the day before $(8 / 11 / 2019)$ and the same day as $(8 / 12 / 2019)$ L. monocytogenes. The large zones $(27.55 \mathrm{~mm}$ and $26.1 \mathrm{~mm}$, respectively) around $1 \mathrm{~A}$ and $1 \mathrm{~B}$ can be seen in the plates on the right.

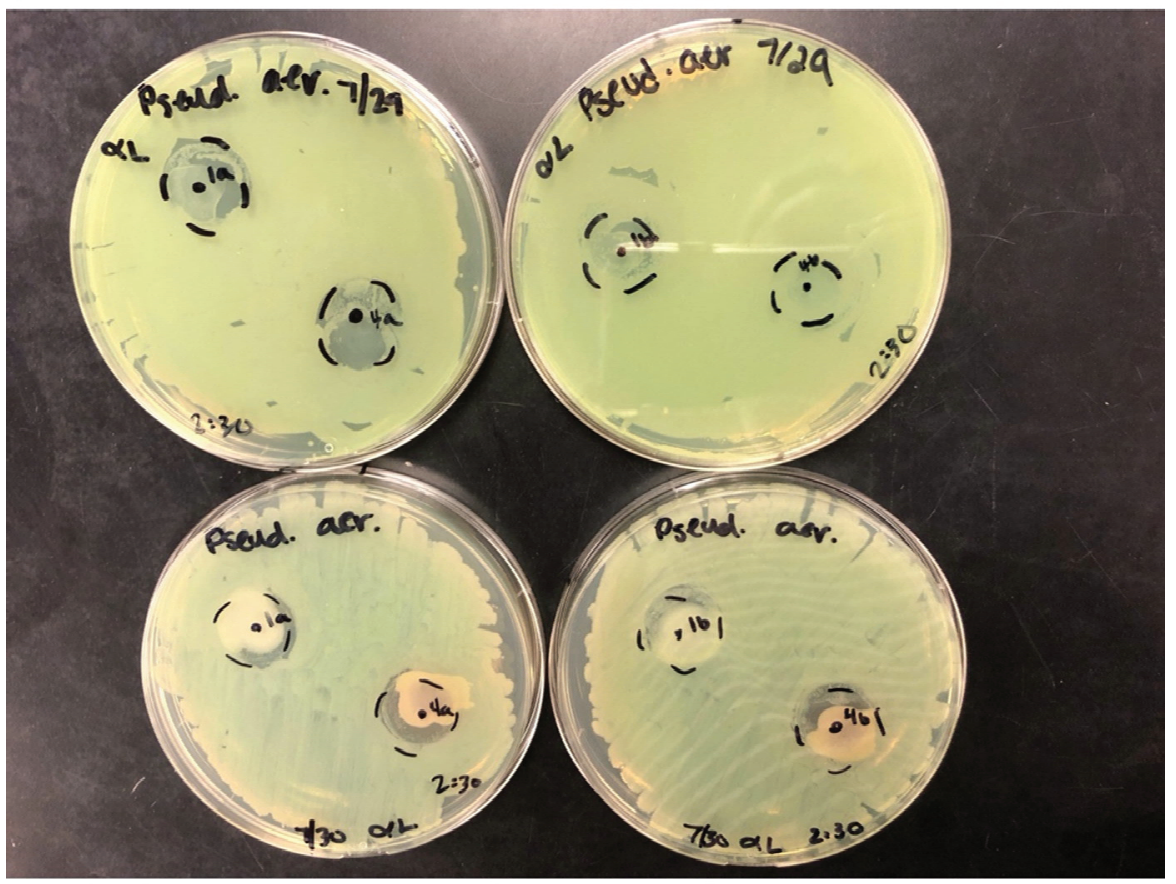

Figure 7. Plates of B. cereus $(1 \mathrm{~A}, 1 \mathrm{~B})$ and $B$. pumilus $(4 \mathrm{~A}$, and $4 \mathrm{~B})$ with $P$. aeruginosa. No zones of inhibition are present. The two plates on the top are the ones when Bacillus strains were plated the day before P. aeruginosa and the two plates on the bottom are the ones when the Bacillus strains were plated on the same day as P. aeruginosa. 


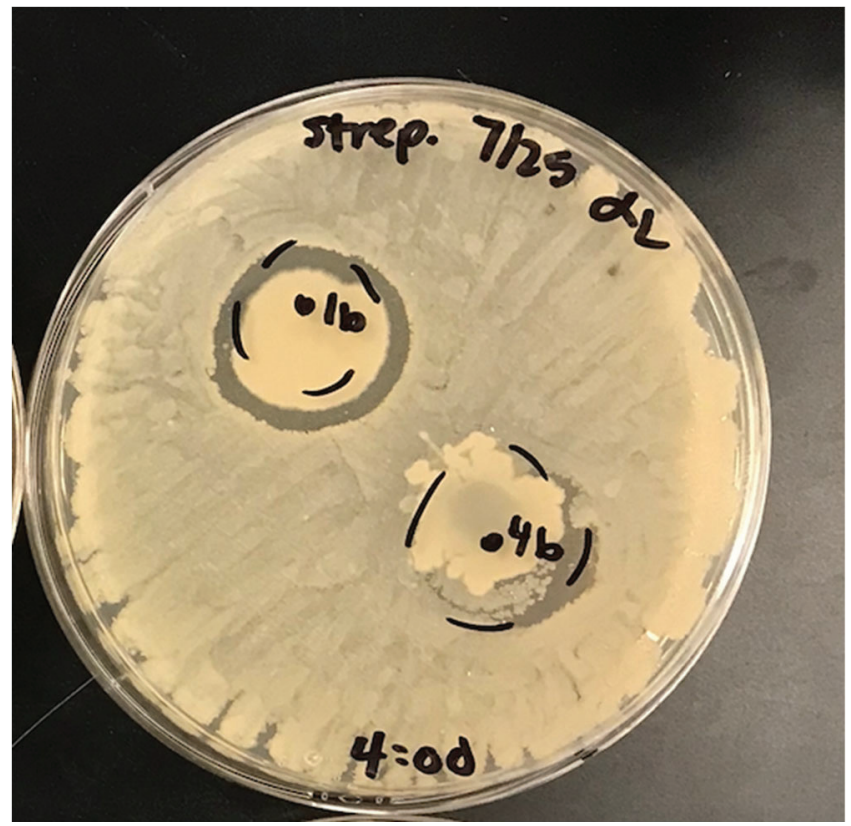

Figure 8. S. pneumoniae with Bacillus cereus (1b) and Bacillus pumilus (4b) when plated on the same day. The zone around $1 \mathrm{~B}$ is $25.2 \mathrm{~mm}$ in diameter.

\section{DISCUSSION}

This study began with the idea of looking for microorganisms living in unusual or challenging environments. Related to this, it was hypothesized that any microorganism living in a challenging environment would benefit from the ability to produce antimicrobial compounds, thus providing a competitive advantage over other microorganisms inhabiting a similar location. The copper roof on Simons Hall provided an additional challenge to microorganisms that might have been deposited there by birds, snow, rain, or wind.

Our results suggest that environmental strains of Bacillus cereus and Bacillus pumilus possess the ability to produce toxic compounds that inhibit the growth of other microorganisms thus enhancing their own chances for survival. The zones of inhibition shown in Figures 2-5 demonstrate that these isolated Bacillus strains are capable of producing these inhibitory compounds throughout their exponential growth phase. This would be quite beneficial to any microorganism competing with others - especially in environments with limited resources.

The production of bacteriocins or bacteriocin-like compounds by bacteria under selective pressure has also been previously documented and is well characterized in Bacillus and lactic acid bacteria (LAB). LABs are frequently isolated from nutrient-rich habitats that have soluble carbohydrates, low oxygen content, and available vitamins and proteins encouraging their survival. ${ }^{15}$ Lewn et al. also determined that $80 \%$ of bacteriocin-producing LAB that were isolated from retail cuts of meat tested positive for a proteinaceous inhibitory substance that was specifically effective at inhibiting the growth of psychotropic pathogens. ${ }^{16}$

Bacteriocins isolated from Bacillus have a broad range of efficacy as they are capable of inhibiting both gram-negative and grampositive bacteria, yeasts, and fungi. ${ }^{13}$ Specifically, the five clinically recognized categories of antibiotics include bacterial peptidoglycan/cell wall disruption, protein biosynthesis, folate biosynthesis, DNA replication and transcription, and disruption of the bacterial membrane. Bacteriocins are known to inhibit four of these pathways (no known bacteriocins inhibit folate biosynthesis) as well as some novel ones including septum formation. ${ }^{17}$ This behavior suggests it may be beneficial to harvest and identify the chemical compound(s) responsible for the toxicity in these Bacillus colonies. The identification of novel bacteriocins may have implications in both human health and control of infectious disease but also as natural alternatives for agriculture applications. For example, bacteriocin producing Bacillus strains inhibit intestinal pathogens and may be a promising probiotic species for humans and livestock. It was also reported that some Bacillus bacteriocins maybe able to control mastitis in dairy cows. ${ }^{18}$ Additionally, these bacteriocins are suggested to have potential as a food preservative for dairy products. ${ }^{19}$

Initial experiments against a laboratory collection of microorganisms have begun. Bacillus cereus was effective in the inhibition of gram-positive L. monocytogenes and S. pneumoniae, while Bacillus pumilus was not effective against either. This suggests differences in 
efficacy between the two strains of Bacillus. Neither strain inhibited P. aeruginosa. B. cereus was most effective when plated the same day as the other microorganisms, indicating that B. cereus does not need a time advantage for growth.

Future studies in our laboratory will be conducted to potentially identify inhibitory compound(s) that are produced by these specific strains of Bacillus. Extraction and purification of a bacteriocin from Bacillus subtilis through gel filtration and thin-layer chromatography has been conducted by other investigators. The isolated bacteriocin had bactericidal activity against some grampositive and gram-negative bacteria. ${ }^{12}$ It is predicted that similar methods could be used to purify the inhibitory molecules from the Bacillus species used in this study. Furthermore, once the inhibitory molecule(s) is isolated, it would be beneficial to subject it to mass spectrophotometry in order to determine what compounds contribute to the biochemical makeup of the inhibitory molecule(s). Additionally, it would be beneficial to determine the stability of these molecules across a range of $\mathrm{pH}$ conditions and temperatures in order to determine biochemical compatibility as a pharmaceutical or agricultural agent.

Bacilli have the ability to grow in environments that are toxic to other bacteria, such as copper, as well as the ability to inhibit the growth of gram-positive bacteria. The conclusion that Bacillus cereus and Bacillus pumilus synthesize inhibitory compounds during all stages of their growth cycles is foundational information that will be used to shape future studies. As the minimum inhibitory concentration of many antibiotics increases along with the rise in antibiotic resistance, it is imperative to study alternative approaches to these existing therapeutic methods. ${ }^{20,21}$ Bacteriocins and conventional antibiotics act on different cell targets, ${ }^{13}$ thus, bacteriocin applications may prove useful in the realm of therapeutic strategies and alternative antibiotics.

\section{CONCLUSIONS}

This study addresses foundational concepts of Bacilli bacteriocins. Bacilli are capable of inhibiting the growth of closely related environmental microbes, and the inhibitory behavior occurs at multiple phases of growth.

\section{ACKNOWLEDGEMENTS}

Authors acknowledge College of St. Benedict / St. John's University for funding support of this project and especially Dr. Ellen Jensen for her time, insights and help in moving this project forward. We also acknowledge Elizabeth Hoppe, Thomas Bell, Anthony Lucca, and Madison Frerk for their assistance with the initial data collection in experiments two and three as well as Sarah Rhodes for assistance with data collection in experiment four.

\section{REFERENCES}

1. Grass, G., Christopher, R., and Marc, S. (2011) Metallic copper as an antimicrobial surface, Applied Environmental Microbiology 77(5), 1541-1547. https:/ / doi.org/10.1128/ AEM.02766-10

2. Montero, D. A., Arellano, C., Pardo, M., Vera, R., Gálvez, R., Cifuentes, M.,María A. Berasain, Marisol Gómez, Claudio Ramírez, and Vidal, R. M. (2019) Antimicrobial properties of a novel copper-based composite coating with potential for use in healthcare facilities, Antimicrobial resistance and infection control 8(3), bttps://doi.org/10.1186/s13756-018-0456-4

3. Rodrigues, V. D., Ossa Henao, D. M., Oliveira V.M., and Ottoboni, L.M. M. (2018) Functional Diversity and Biotechnological Potential of Heterotrophic Bacteria Isolated from Brazilian Copper Mine Environments, Oxidation Communications 41, 440-461.

4. Turnbull, P. C. B., Hutson, R. A., Ward, M. J., Jones, M. N., Quinn, C. P., Finnie, N. J., Duggleby, J. M., Kramer, and Melling, J. (1992) Bacillus anthracis but not always anthrax, Journal of Applied Bacteriology 72(1), 21-28. https://doi.org/10.1111/j.1365-2672.1992.tb04876.x

5. Thwaite, J. E., and Atkins, H. S. (2012) Bacillus: Anthrax; food poisoning, In Medical Microbiology 18 ${ }^{\text {th }}$ ed., 237-244, Churchill Livingstone, https://doi.org/10.1016/B978-0-7020-4089-4.00036-6

6. Nicholson, W. L. (2002) Roles of Bacillus endospores in the environment, Cellular and Molecular Life Sciences 59(3), 410416. https:// doi.org/10.1007/s00018-002-8433-7

7. Rafii, F., Williams, A. J., Park, M., Sims, L. M., Heinze, T. M., Cerniglia, C. E., and Sutherland, J. B. (2009) Isolation of bacterial strains from bovine fecal microflora capable of degradation of ceftiofur, Veterinary microbiology 139(1-2), 89-96. https:// doi.org/1016/j.vetmic.2009.04.023

8. Bernhard, K., Schrempf, H., and Goebel, W. (1978) Bacteriocin and antibiotic resistance plasmids in Bacillus cereus and Bacillus subtilis, Journal of bacteriology 133(2), 897-903. https:/ / doi.org/10.1128/JB.133.2.897-903.1978

9. Marahier, M. A., Nakano, M., and Zuber, P. (1993) Regulation of peptide antibiotic production in Bacillus, Molecular microbiology 7(5), 631- 636. bttps:// doi.org/10.1111/j.1365-2958.1993.tb01154.x

10. Cotter, P., Hill, C. and Ross, R. (2005) Bacteriocins: developing innate immunity for food, Nat Rev Microbiol 3, $777-788$. https:// doi.org/10.1038/nrmicro1273

11. Sharma, G., Dang, S., Gupta, S., and Gabrani, R. (2018) Antibacterial Activity, Cytotoxicity, and the mechanism of action of bacteriocin from Bacillus subtilis GAS101, Medical Principles and Practice 27(2), 186-192. bttps://doi.org/10.1159/000487306 
12. Babasaki, K., Takao, T., Shimonishi, Y., and Kurahashi, K. (1985) Subtilosin A, a new antibiotic peptide produced by Bacillus subtilis 168: isolation, structural analysis, and biogenesis, J. Biochem 98(3), 585-603. https:// doi.org/10.1093/oxfordjournals.jbchem.a135315

13. Abriouel, H., Franz, C. M., Omar, N. B., and Gálvez, A. (2011) Diversity and applications of Bacillus bacteriocins, FEMS microbiology reviews, 35(1), 201-232. https:// doi.org/10.1111/j.1574-6976.2010.00244.x

14. Bottone, E.J, and Peluso, R.W. (2003) Production by Bacillus pumilus (MSH) of an antifungal compound that is active against Mucoraceae and Aspergillus species: preliminary report, Journal of Medical Microbiology 52, 69-74. https:// doi.org/10.1099/jmm.0.04935-0

15. López-Cuellar, M., Rodriguez-Hernandez, A., and Chavarria-Hernandez, N. (2016) LAB bacteriocin applications in the last decade, Biotechnology \& Biotechnological Equipment 30(6), 1039-1050. https:/ / doi.org/ 10.1080/13102818.2016.1232605

16. Lewus, C. B., Kaiser, A. L. A. N., and Montville, T. J. (1991) Inhibition of food-borne bacterial pathogens by bacteriocins from lactic acid bacteria isolated from meat, Applied Environmental Microbiology 57(6), 1683-1688. bttps:/ / doi.org/10.1128/AEM.57.6.1683-1688.1991

17. Cavera, V. L., Arthur, T. D., Kashtanov D., and Chikindas, M.L. (2015) Bacteriocins and their position in the next wave of conventional antibiotics, International Journal of Antimicrobial Agents 46(5), 494-501. https:// doi.org/10.1016/j.ijantimicag.2015.07.011

18. Barboza-Corona, J. E., de la Fuente-Salcido, N., Alva-Murillo, N., Ochoa-Zarzosa, A., and López-Meza, J. E. (2009) Activity of bacteriocins synthesized by Bacillus thuringiensis against Staphylococcus aureus isolates associated to bovine mastitis, Veterinary microbiology 138(1-2), 179-183. https:// doi.org/10.1016/j.vetmic.2009.03.018

19. Sharma, N., Attri, A., and Gautam, N. (2009) Purification and characterization of bacteriocin like substance produced from Bacillus lentus with perspective of a new biopreservative for food preservation, Biological Sciences - PJSIR 52(4), 191-199. Retrieved from https://v2.pjsir.org/index.php/biological-sciences/article/view/547

20. Clardy, J., Fischback, M.A., and Currie, C.R. (2009) The natural history of antibiotics, Curr Biol 19(11), R437-R441. https://doi.org/10.1016/j.cub.2009.04.001

21. Fernandez, L., Breidenstein, E., and Hancock, R. (2012) Importance of Adaptive and Stepwise Changes in the Rise and Spread of Antimicrobial Resistance, In Antimicrobial Resistance in the Environment 43-73, John Wiley \& Sons, Inc., New Jersey.

\section{ABOUT STUDENT AUTHORS}

Stiller graduated from the College of St. Benedict in 2019 with a Bachelor of Arts degree in Biology. She conducted this research to fulfill her senior capstone requirement. Stiller continued the research the following summer and presented her findings at the St. Jude's Research Hospital's 2019 symposium.

\section{PRESS SUMMARY}

Copper presents unique challenges for bacterial growth; however, Bacillus harvested from a copper roof displayed inhibitory behavior against other bacterial colonies. It was predicted that an inhibitory mechanism was occurring at a specific stage of Bacillus' growth cycle, but this study illustrated that the inhibitory mechanism was occurring at all stages of bacterial growth. This is foundational information and will contribute to future studies involved in identifying and isolating the antimicrobial compound or molecule. 